Araştırma Makalesi-Research Article

\title{
Keten Kumaşların Isırgan Otu ile Boyanabilirliğinin İncelenmesi
}

\author{
Fazlıhan YILMAZ $^{1^{*}}$
}

Geliş / Received: $30 / 03 / 2020$

Revize / Revised: 25/05/2020

Kabul / Accepted: 28/05/2020

ÖZ

İnsanlar, seçme şanslarının olduğu her fırsatta ilk başta doğal kökenli ürünleri tercih etmektedirler. Bunun asıl sebebi ise kimyasal kökenli ürünlerin sağlığa olan olumsuz etkileridir. Bu bağlamda, yapılan bu çalışmada keten kumaşların ısırgan otu ile boyanabilirliğinin araştırılması amaçlanmıştır. Isırgan otu kuru halde temin edildikten sonra değirmenden geçirilerek öğütülmüş ve boyama denemelerinde öğütülmüş olan bu kısım kullanılmıştır. Boyamada 6 farklı metal tuzu mordan maddesi olarak kullanılmıştır. Ayrıca mordan maddesi kullanımı olmadan da boyama denemeleri gerçekleştirilmiştir. Kullanılan bu 6 farklı mordan maddesi ise; Potasyum alüminyum sülfat (Şap) $\left(\mathrm{KAlSO}_{4} \cdot 10 \mathrm{H}_{2} \mathrm{O}\right)$, çinko klorür $\left(\mathrm{ZnCl}_{2}\right)$, potasyum dikromat $\left(\mathrm{K}_{2} \mathrm{Cr}_{2} \mathrm{O}_{7}\right)$, demir II sülfat $\left(\mathrm{FeSO}_{4} .7 \mathrm{H}_{2} \mathrm{O}\right)$, kalay II klorür $\left(\mathrm{SnCl}_{2} \cdot 2 \mathrm{H}_{2} \mathrm{O}\right)$, bakır II sülfat $\left(\mathrm{CuSO}_{4} .5 \mathrm{H}_{2} \mathrm{O}\right)$ dır. Boyama işlemleri tamamlandıktan sonra boyanmış olan kumaş numunelerinin spektrofotometre yardımıyla CIELAB (L*, a*, b*, $\mathrm{C}^{*}$ ve $\mathrm{h}^{\circ}$ ) ve $\mathrm{K} / \mathrm{S}$ değerleri ölçülmüştür. Ayrıca boyanmış olan kumaş numunelerinin yıkama ve 1şık haslığı testleri de yapılmıştır. Bu işlemler sonucunda 1sırgan otunun keten kumaşların renklendirilmesinde kullanılabileceği tespit edilmiştir.

Anahtar Kelimeler- Doğal boya, Mordan, Isırgan otu, Renk, Haslık

1*Sorumlu yazar iletişim: fazlihan.yilmaz@atauni.edu.tr (https://orcid.org/0000-0003-2778-163X)

Atatürk Üniversitesi, Güzel Sanatlar Fakültesi, Tekstil ve Moda Tasarımı Bölümü, Erzurum 


\title{
Investigation of the Dyeability of Linen Fabrics with Nettle
}

\begin{abstract}
People always prefer products of natural origin whenever they have the opportunity to choose. The main reason for this is the negative effects of products of chemical origin on health. In this context, this study aimed to investigate the dyeability of linen fabrics with nettle. After the nettle was obtained in a dry state, it was milled by passing through the mill and this part, which was ground in dyeing experiments, was used. Six different metal salts were used as mordant in dyeing processes. In addition, dyeing experiments were carried out without the use of mordant. These 6 different mordant substances used are; Potassium aluminum sulfate (Alum) (KAlSO $\left.4.10 \mathrm{H}_{2} \mathrm{O}\right)$, zinc chloride $\left(\mathrm{ZnCl}_{2}\right)$, potassium dichromate $\left(\mathrm{K}_{2} \mathrm{Cr}_{2} \mathrm{O}_{7}\right)$, iron II sulfate $\left(\mathrm{FeSO}_{4} \cdot 7 \mathrm{H}_{2} \mathrm{O}\right)$, tin II chloride $\left(\mathrm{SnCl}_{2} .2 \mathrm{H}_{2} \mathrm{O}\right)$, copper II sulfate $\left(\mathrm{CuSO}_{4} .5 \mathrm{H}_{2} \mathrm{O}\right)$. After the dyeing process, CIELAB $(\mathrm{L} *, \mathrm{a} *, \mathrm{~b} *, \mathrm{C} *$ and $\mathrm{h}^{\circ}$ ) and $\mathrm{K} / \mathrm{S}$ values of the dyed fabric samples were measured with a spectrophotometer. In addition, washing and light fastness tests of the dyed fabric samples were carried out. As a result of these processes, it was determined that nettle can be used for coloring linen fabrics.
\end{abstract}




\section{GİRIŞ}

İnsanoğlu başlangıçta, yaşamın devam ettirebilmek için bitkileri beslenme amacıyla kullanmıştır. Daha sonrasında barınma ve örtünme ihtiyacını yine bitkisel liflerle ve bunun yanında hayvansal lifleri kullanarak gidermiştir. Bitkisel kaynaklı doğal boyarmaddeleri ise estetik kaygıyla, çevresini güzelleş̧tirme ve statü belirlemek amacıyla bitkilerden yararlanarak elde etmiştir [1]. Türkiye'de doğal boyacıllk bir ata sanatı olarak uzun sürelerden beri yapılmıştır. Doğal Boyacılık Türklerde ileri düzeylerde uygulanmış ve Dünyada doğal boyacılık açısından örnek teşkil etmiştir [2]. Birçok tekstil mamulünün boyanmasında kullanılan ve dünyaca ünlü olan "Türk Kırmızısı" veya "Edirne Kırmızısı" adıyla anılan doğal boyarmadde de mevcuttur. Bu da kök boyadır [3].

Gelişen teknoloji, çevre kirliliğini de yanında getirmiş̧ir. İncelen ozon tabakası, artan hava ve su kirliliği, azalan yeşil alanlar gibi olumsuzluklar karșısında özellikle gelişmiş ülkelerde duyarlı bir kamuoyu oluşmaya başlamıştır. Günümüzde çevre dostu tekstiller konusu giderek artan bir önem kazanmaktadır [4]. Son yıllarda tekstil terbiye işlemlerinde kullanılan sentetik boyarmaddelerin ve pigmentlerin kullanımı insan sağlığına ve çevreye verdiği zarardan ötürü tartışılmaktadır. Bu sebeple, biyolojik olarak parçalanabilirliği, toksik olmaması, insan sağlığı ve atık su kontaminantı için herhangi bir sorun oluşturmaması sebebiyle doğadaki bitkilerden elde edilen doğal boyarmaddelerin kullanımı artmaya başlamıştır [5]. Çevre ile ilgili endişeler ve farkındalık, çevreyi ve insan sağlığını daha az etkileyen sürdürülebilir ürün ve süreçlerin geliştirilmesini desteklemiştir [6]. Geçmişte yaygın olarak kullanılan kimyasal maddelere alternatif \%100 doğal ürünler kullanılması yönünde araştırmalar giderek önem kazanmaktadır. Boyarmadde ihtiva eden atık sular üzerindeki kısıtlamalar da araştırmacıları doğal boyarmaddeleri kullanmaya yöneltmiştir. Çevreyi kirletmeyen doğal boyarmaddeler mordanların da kullanılmasıyla birlikte iyi haslık özellikleri ve çok sayıda farklı renkler elde etmeye uygundur [7]. Doğal boyarmaddeler çevre dostu, tehlikesiz ve sürdürülebilirdir [8]. Doğal boyarmadde kaynakları temel olarak üç gruba ayrılmaktadır. Bu gruplar; bitkisel, hayvansal ve madensel boyarmaddelerdir. $\mathrm{Bu}$ gruplar içerisinde, bitkisel boyarmaddeler en fazla kaynağı sunmaktadırlar. Yalnızca tekstil endüstrisinde değil gıda, kozmetik, tıp gibi birçok endüstri alanında doğal boyalar üzerine araştırmalar yapılmaktadır [9]. Bitkiden elde edilen renk tonu, bitkinin toplandığı mevsime, nasıl yetiştirildiğine ve toprak koşullarına göre değişecektir. [10].

Isırgan (Urtica), ısırgangiller (Urticaceae) familyasının Urtica cinsinden Mayıs-Ağustos ayları çiçek açan bir bitkidir [11]. Isırgan otu ülkemizde tarla, yol ve orman kıyılarında doğal olarak bulunan tek veya otsu bir tıbbi bitkidir. Özellikle Karadeniz Bölgesinde çok yoğun olarak yayılış gösteren bitki kimyasal içerik yönünden oldukça zengin, yüzyılardan beri, ilaç, gıda, lif, boya ve kozmetik olarak kullanılmaktadır [12]. Adını üzerinde bulunan yakıcı tüylerden alan isırgan otu, ailesinde 48 cins ve 1050 tür sinıflandırılmaktadır [13]. Yetiştiriciliği diğer bitkilere baskın olması ve nemli alanlarda hızla gelişmesi sebebiyle basittir [14].

Literatürde 1sırgan otu kullanılarak yapılan boyama denemeleri mevcuttur. Örneğin; 2015 yllında Karabulut'un yaptı̆̆ı çalışmada, farklı bitkilerin yanı sıra ısırgan otu kullanarak da pamuklu kumaşların renklendirilebilirliğ̣i araştırılmıştır. Sonuç olarak pamuklu kumaşların isırgan otu kullanılarak renklendirilebileceğini tespit etmiştir [15]. 2015 yılında yapılan bir başka çalışmada ise farklı bitkiler ve ısırgan otu kullanılarak akrilik lifinin boyanabilirliği incelenmiştir. Yapılan çalışma sonucunda akrilik liflerinin ısırgan otu yardımıyla boyanabileceği tespit edilmiştir [16].

Son zamanlarda yaşanan gelişmelerle birlikte doğal maddelere her alanda ilgi artmıştır. Bu bağlamda yapılan bu çalışmada tekstil boyamacılığında bir bitkisel kaynağın kullanılıp kullanılmayacağı araştırılmıştır. Bu bitkisel boyarmadde kaynağı ise ısırgan otudur. Böylece kimyasal boyarmaddelerin zararlı etkilerinden kaçınılacak ve doğal boyarmaddelerin tekrardan önem kazanması hedeflenmektedir.

\section{MATERYAL VE METOT}

Çalışma kapsamında \%100 keten kumaşın ısırgan otu ile boyanabilirliği araştırılmıştır. Keten kumaş boyama işlemlerine hazır halde gerekli ön işlemden geçmiş şekilde temin edilmiştir. Isırgan otu ise yapılan boyama denemelerinde bitkisel boyarmadde kaynağı olarak seçilmiştir. 


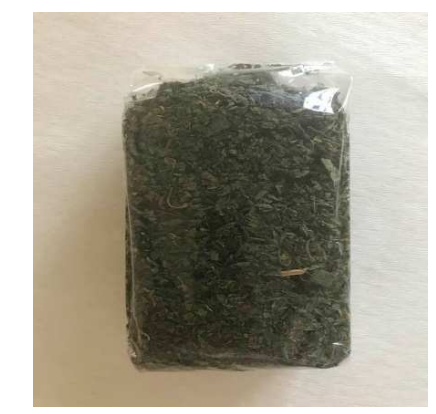

Şekil 1. Kuru halde tedarik edilen isırgan otu

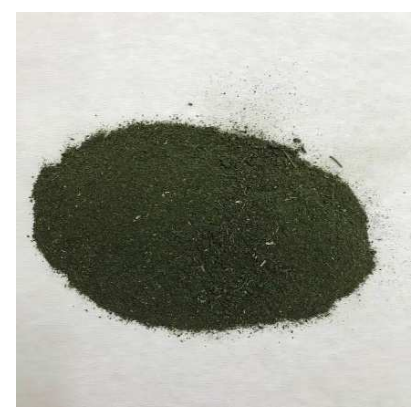

Şekil 2. Öğütülmüş 1sırgan otu

Şekil 1.'deki gibi kuru halde tedarik edilen 1sırgan otu boyama işleminde kullanılmadan önce öğütücü yardımıyla ögüutülmüş ve Şekil 2'deki forma getirilmiştir ve yapılan bütün boyama denemelerinde ögüutülmüş olan ısırgan otu herhangi bir ön işlem görmeden direkt olarak kullanılmıştır.

Boyama denemeleri mordan maddesi kullanılmadan ve ayrıca mordan maddesi kullanılarak da yapılmıştır. Mordan maddesi olarak ise 6 farklı metal tuzu kullanılmıştır. Bunlar; Potasyum alüminyum sülfat (Şap) $\left(\mathrm{KAlSO}_{4} \cdot 10 \mathrm{H}_{2} \mathrm{O}\right)$, çinko klorür $\left(\mathrm{ZnCl}_{2}\right)$, potasyum dikromat $\left(\mathrm{K}_{2} \mathrm{Cr}_{2} \mathrm{O}_{7}\right)$, demir II sülfat $\left(\mathrm{FeSO}_{4} .7 \mathrm{H}_{2} \mathrm{O}\right)$, kalay II klorür $\left(\mathrm{SnCl}_{2} \cdot 2 \mathrm{H}_{2} \mathrm{O}\right)$, bakır II sülfat $\left(\mathrm{CuSO}_{4} \cdot 5 \mathrm{H}_{2} \mathrm{O}\right)$ dır.

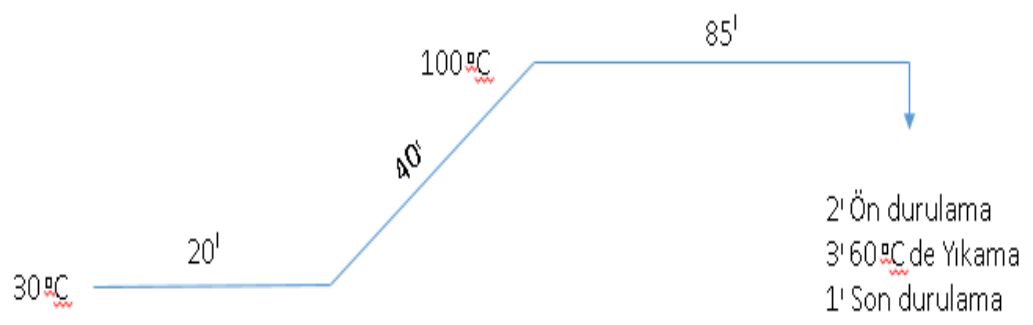

Şekil 3. Boyama diyagramı

Boyama işlemine geçilmeden önce keten kumaş numunelerinin boyama denemelerine hazır hale getirilebilmesi için 2 gram olarak kesilme işlemleri gerçekleştirilmiştir. Daha önce de bahsedildiği gibi 1sırgan otu boyama işlemlerinde herhangi bir ekstraksiyon düzeneği kullanılmadan direkt olarak boyama banyosuna eklenmiştir. Yani öğütülmüş olan ısırgan otu direkt olarak kullanılmıştır. Flotte oranı bütün boyama denemeleri için kumaş ağırlığıyla orantılı olarak 1:75 oranında ayarlanmıştır. Mordan maddesi konsantrasyonu ise kumaş ağırlığıyla orantılı olarak \%3 seçilmiştir (şap hariç). Şap mordan maddesi kullanılan boyama denemelerinde ise mordan maddesi kumaş ağırlığıyla orantılı şekilde \%25 olarak ayarlanmıştır. Yapılan boyama işlemlerinde birlikte mordanlama yöntemi kullanılmıştır. Yani kumaş, mordan maddesi ve isırgan otu hep birlikte boyama banyosuna eklenmiştir. Isırgan otu kullanılarak yapılan boyama işlemlerinde bitkisel boyarmadde miktarı (kumaş ağırlığı/bitkisel kaynak) ise 2 farklı oran olan, 1:0,5 ve 1:2 olarak ayarlanmıştır. Bu işlemler gerçekleştirildikten sonra boyama denemelerine başlanılmıştır.

Şekil 3'de 1sırgan otu kullanılarak keten kumaşların boyanma işleminde kullanılan boyama diyagramı sunulmuştur. Bu diyagram incelendiğinde keten kumaş, ısırgan otu ve eğer kullanılacaksa mordan maddesi boyama banyosuna eklenildikten sonra $30{ }^{\circ} \mathrm{C}$ 'de boyama işlemine başlanılmıştır. Bu sıcaklıkta 20 dakika boyunca işlem gerçekleştirildikten sonra 40 dakikada $100{ }^{\circ} \mathrm{C}$ 'ye çıkılmıştır. Daha sonrasında 85 dakika boyunca $100{ }^{\circ} \mathrm{C}^{\prime}$ de boyama işlemi gerçekleştirilmiştir. Boyama denemeleri tamamlandıktan sonra keten kumaş 
numuneleri boya banyosundan alınarak ilk önce 2 dakikalık bir ön durulama işlemi görmüştür. Daha sonrasında boyanmış olan keten kumaş numuneleri 3 dakika boyunca $60{ }^{\circ} \mathrm{C}$ 'de asıl yıkama işlemine alınmıştır. Asıl yıkama işlemi de tamamlandıktan sonra son olarak keten kumaş numuneleri 1 dakikalık durulama işlemi görmüştür. Boyama ve yıkama adımı da bitirildikten sonra hiçbir 1sıtıcı kullanılmadan keten kumaş numuneleri oda sıcaklığında kurumaya bırakılmıştır.

Boyanmış, yıkanmış ve kurutulmuş olan kumaş numuneleri gerekli ölçümleri yapılmak üzere hazır hale getirilmiştir. İlk başta boyalı kumaş numunelerinin renk ölçüm testleri gerçekleştirilmiştir. Yani spektrofotometre yardımıyla CIELAB $\left(L^{*}, a^{*}, b^{*}, C^{*} v e h^{\circ}\right)$ ve K/S (renk verimliliği) değerleri ölçülmüştür. Daha sonrasında boyanmış olan keten kumaş numunelerinin kullanım açısından gerekli özellikleri gösterip gösteremediğinin araştırılması için yıkama ve 1 şık haslığı testleri de gerçekleştirilmiştir. Işık haslığı testi ISO 105-B02 standardına göre (mavi skala) [17] ve yıkama haslığı testi ISO 105-C10standardına göre (gri skala) [18] değerlendirilmiştir. Bütün bu yapılan ölçümlerin sonuçları ise 3. Bölümde tablolar halinde düzenlenerek sunulmuştur.

\section{BULGULAR VE TARTIŞMA}

Yapılan bu çalışmada ısırgan otu kullanılarak keten kumaşların renklendirilip renklendirilemeyeceği araştırılmıştır. Materyal-Metot'da sunulan bilgiler doğrultusunda boyama denemeleri gerçekleştirilmiştir ve bu bölümde ise bu denemeler neticesinde elde edilen bulgular sunulmuştur.

L* açıklık eksenidir. Bu değer ideal siyahta sıfırdan başlayıp, ideal beyaz için 100'e ulaşır. Yani L* değeri ideal siyah için sıfır, ideal beyaz için 100'dür. "a*” kırmız1-yeşil eksenini, "b*" sarı-mavi eksenini, "C" doygunluğu ve " $h{ }^{\circ}$ " renk cinsini $\left(h=0^{\circ}\right.$ Kırmızı, $h=90^{\circ}$ Sarı, $h=180^{\circ}$ Yeşil, $h=270^{\circ}$ Mavi) vermektedir [19].

Tablo 1'deki L* değerleri incelendiğinde, mordan maddesi kullanılmadan 1:0,5 boyama konsantrasyonunda yapılan boyama deneyinde $L^{*}$ değeri 80,74 olarak tespit edilmiştir. Yine mordan maddesi kullanılmadan 1:2 boyama konsantrasyonunda yapılan boyama işleminde ise L* değeri 77,23 olarak karşımıza çıkmaktadır. Yani kullanılan bitkisel boyarmadde miktarı arttığında L* değerinde düşüş meydana gelmiştir. Genel olarak yapılan bütün boyama denemeleri incelendiğinde en yüksek L* değeri 84,68 olarak bulunurken en düşük $L^{*}$ değeri ise 74,37 olarak gözlemlenmiştir. En yüksek $L^{*}$ değerine 1:0,5 boyama konsantrasyonunda şap mordan maddesi kullanılarak yapılan boyama denemesinde ulaşılmıştır. En düşük $\mathrm{L}^{*}$ değeri ise 1:2 boyama konsantrasyonunda çinko klorür mordan maddesi kullanılarak elde edilmiştir. Genel olarak boyama konsantrasyonu arttığında $L^{*}$ değerlerinde düşüş meydana gelmiştir.

Isırgan otu kullanılarak boyanmış olan keten kumaşlarda bej, açık yeşil, açık sarı ve krem rengi elde edilmiştir. Örneğin; Kalay II klorür mordan maddesi kullanılarak 1:2 boyama konsantrasyonunda yapılan boyama deneyinde $\mathrm{a}^{*}=-0,23, \mathrm{~b}^{*}=11,96 \mathrm{ve} \mathrm{h}^{\mathrm{o}}=91,13$ olarak ölçülmüştür. Bu boyama deneyinde renk açık sarı olarak algılanmaktadır. Bir başka boyama denemesinde ise 1:2 boyama konsantrasyonunda bakır II sülfat mordan maddesi kullanılmış ve $\mathrm{h}^{\circ}=99,61, \mathrm{a}^{*}=-1,72$ ve $\mathrm{b}^{*}=10,16$ olarak tespit edilmiştir. Bu boyama denemesinde ise renk açık yeşil olarak algılanmaktadır. Son olarak mordan maddesi kullanılmadan 1:0,5 boyama konsantrasyonunda yapılan boyama işleminde ise $a^{*}=-0,63, b^{*}=8,88$ ve $h^{\circ}=94,06$ olarak ölçülmüştür. Bu boyama denemesinde elde edilen renk ise krem rengi olarak algılanmaktadır.

Tablo 1'deki K/S (renk verimliliği) değerleri incelendiğinde ise mordan maddesi kullanılmadan 1:2 boyama konsantrasyonunda 0,57 değerinin elde edildiği gözlemlenmiştir. Boyama konsantrasyonu düştüğünde yani 1:0,5 konsantrasyonda mordan maddesi kullanılmadan yapılan boyama denemesinde ise 0,42 değerinin elde edildiği tespit edilmiştir. Yani boyama işleminde kullanılan bitkisel boyarmadde kaynağının miktarı arttığında renk verimliliği değerinde de artış olduğu görülmüştür. En düşük K/S değeri 0,38 dir. Bu değere 1:0,5 boyama konsantrasyonunda şap mordan maddesi kullanılarak yapılan boyama denemesinde ulaşılmıştır. En yükssek değer ise yine şap mordan maddesi kullanılarak 1:2 boyama konsantrasyonunda yapılan boyama denemesinde elde edilmiştir. $\mathrm{Bu}$ değer ise 0,79 olarak karşımıza çıkmaktadır. İstisnasız olarak boyarmadde konsantrasyonu arttığında K/S değerlerinde de artış meydana gelmiştir. 
Tablo 1. Isırgan otu kullanılarak boyanmış olan keten kumaşların CIELAB $\left(L^{*}, a^{*}, b^{*}, C^{*} v e h^{\circ}\right)$ ve K/S değerleri

\begin{tabular}{|c|c|c|c|c|c|c|c|c|}
\hline \multirow{2}{*}{$\begin{array}{c}\text { Boyama } \\
\text { Konsantrasyonu }\end{array}$} & \multirow{2}{*}{ Mordan tipi } & \multirow{2}{*}{$\begin{array}{c}\text { Elde Edilen } \\
\text { Renkler }\end{array}$} & \multirow{2}{*}{$\mathbf{K} / \mathbf{S}$} & \multicolumn{5}{|c|}{ CIE L*a*b* (D65) } \\
\hline & & & & $\mathbf{L}^{*}$ & $\mathbf{a}^{*}$ & $\mathbf{b}^{*}$ & $\mathrm{C}^{*}$ & $\mathbf{h}^{\mathbf{o}}$ \\
\hline 1:0,5 & Mordansız & & 0,42 & 80,74 & $-0,63$ & 8,88 & 8,91 & 94,06 \\
\hline \multirow[t]{3}{*}{$1: 2$} & Mordansız & & 0,57 & 77,23 & $-1,11$ & 9,44 & 9,5 & 96,74 \\
\hline & Bakır II Sülfat & & 0,5 & 77,93 & $-0,28$ & 9,16 & 9,17 & 91,78 \\
\hline & Kalay II Klorür & & 0,41 & 83,66 & $-0,21$ & 9,93 & 9,94 & 91,19 \\
\hline \multirow[t]{4}{*}{$1: 0,5$} & Demir II Sülfat & & 0,44 & 78,94 & $-1,26$ & 9,12 & 9,21 & 97,85 \\
\hline & Çinko Klorür & & 0,48 & 78,72 & $-1,53$ & 9,94 & 10,06 & 98,73 \\
\hline & Potasyum Dikromat & & 0,59 & 78,2 & $-0,24$ & 11,46 & 11,46 & 91,21 \\
\hline & Şap & & 0,38 & 84,68 & $-0,65$ & 11,52 & 11,54 & 93,22 \\
\hline & Bakır II Sülfat & & 0,61 & 76,82 & $-1,72$ & 10,16 & 10,31 & 99,61 \\
\hline & Kalay II Klorür & & 0,62 & 80,42 & $-0,23$ & 11,96 & 11,96 & 91,13 \\
\hline \multirow[t]{4}{*}{$1: 2$} & Demir II Sülfat & & 0,68 & 74,82 & $-2,05$ & 10,88 & 11,07 & 100,67 \\
\hline & Çinko Klorür & & 0,71 & 74,37 & $-1,67$ & 10,95 & 11,08 & 98,66 \\
\hline & Potasyum Dikromat & & 0,65 & 77,49 & $-0,37$ & 12 & 12 & 91,77 \\
\hline & Şap & & 0,79 & 78,08 & $-0,47$ & 13,52 & 13,53 & 91,97 \\
\hline
\end{tabular}

Daha öncede bahsedildiği gibi ısırgan otu kullanılarak boyanmış olan keten kumaşların ışık ve yıkama haslığ 1 testleri de gerçekleştirilmiştir. Bu testler sonucunda da elde edilen değerler Tablo 2'de sunulmuştur.

Tablo 2'deki 1şık haslığı test sonuçları incelendiğinde, mordan maddesi kullanılmadan 1:0,5 boyama konsantrasyonunda yapılan boyama deneyinde 1şık haslığı değeri 4 olarak tespit edilmiştir. Aynı şekilde yine mordan maddesi kullanılmadan 1:2 boyama konsantrasyonunda yapılan boyama denemesinde ise 1şık haslığ değeri 4-5 olarak ölçülmüştür. Burada görülmektedir ki mordan maddesi kullanılmadan yapılan boyama denemesinde bitkisel boyarmadde miktarı arttığında 1şık haslığı değerinde de artış meydana gelmiştir. Genel olarak 1şık haslığı değerleri incelendiğinde ise yapılan boyama deneylerinde bitkisel boyarmadde miktarı arttığında 1şık haslığı değerleri ya artmıştır ya da sabit kalmıştır. Işık haslığı açısından en yüksek 4-5 değeri, 1:2 mordansız boyamaya ek olarak aynı zamanda demir II sülfat ve potasyum dikromat mordan madddelerinin kullanımıyla yapılan boyama denemelerinde elde edilmiştir. 
Isırgan otu ile boyanmış olan keten kumaş numunelerinin yıkama haslık testleri de yapılmıştır. Burada L değeri keten kumaşı kirletme değeridir. Genel itibariyle yıkama haslığı test sonuçları incelendiğinde hem referans kumaşı kirletme açısından hem de renk değişimi açısından 4 ile 5 arasında değişen değerlerin elde edildiği gözlemlenmiştir. Renk değişimi açısından en düşük değer 4 olarak, bakır II sülfat mordan maddesi kullanılarak 1:0,5 boyama konsantrasyonunda yapılan boyama deneyinde elde edilmiştir. En yüksek değer ise 5 olarak, birden fazla boyama denemesinde bulunmuştur. Referans kumaşı kirletme değeri olarak ise bütün boyama denemelerinde 5 değerine ulaşılmıştır.

Tablo 2. Boyanmış keten kumaşların ışık ve yıkama haslığı test sonuçları

\begin{tabular}{|c|c|c|c|c|c|c|}
\hline \multirow{4}{*}{ Mordan Maddesi } & \multicolumn{6}{|c|}{ Boyama Konsantrasyonu } \\
\hline & \multicolumn{3}{|c|}{$1: 0,5$} & \multicolumn{3}{|c|}{$1: 2$} \\
\hline & \multirow[t]{2}{*}{ Işık Haslığı } & \multicolumn{2}{|c|}{$\begin{array}{l}\text { Yıkama } \\
\text { Haslığı }\end{array}$} & \multirow[t]{2}{*}{ Işılk Haslığı } & \multicolumn{2}{|c|}{$\begin{array}{l}\text { Yıkama } \\
\text { Haslığı }\end{array}$} \\
\hline & & $\mathrm{R}$ & $4-5$ & & $\mathrm{R}$ & $4-5$ \\
\hline \multirow[t]{2}{*}{ Mordansız } & 4 & $\mathrm{~L}$ & 5 & $4-5$ & $\mathrm{~L}$ & 5 \\
\hline & & $\mathrm{R}$ & 4 & & $\mathrm{R}$ & $4-5$ \\
\hline \multirow[t]{2}{*}{ Bakır II Sülfat } & 4 & $\mathrm{~L}$ & 5 & 4 & $\mathrm{~L}$ & 5 \\
\hline & & $\mathrm{R}$ & 5 & & $\mathrm{R}$ & 5 \\
\hline \multirow[t]{2}{*}{ Kalay II Klorür } & 4 & $\mathrm{~L}$ & 5 & 4 & $\mathrm{~L}$ & 5 \\
\hline & & $\mathrm{R}$ & 5 & & $\mathrm{R}$ & 5 \\
\hline \multirow[t]{2}{*}{ Demir II Sülfat } & 4 & $\mathrm{~L}$ & 5 & $4-5$ & $\mathrm{~L}$ & 5 \\
\hline & & $\mathrm{R}$ & 4 & & $\mathrm{R}$ & 5 \\
\hline Çinko Klorür & 4 & $\mathrm{~L}$ & 5 & 4 & $\mathrm{~L}$ & 5 \\
\hline \multirow{3}{*}{ Potasyum Dikromat } & 4 & $\mathrm{R}$ & 5 & $4-5$ & $\mathrm{R}$ & 5 \\
\hline & 4 & $\mathrm{~L}$ & 5 & 4-J & $\mathrm{L}$ & 5 \\
\hline & & $\mathrm{R}$ & $4-5$ & & $\mathrm{R}$ & $4-5$ \\
\hline Şap & 4 & $\mathrm{~L}$ & 5 & 4 & $\mathrm{~L}$ & 5 \\
\hline
\end{tabular}

\section{SONUÇLAR}

Renk hayatımızın her alanında olduğu gibi tekstil sektöründe de önde gelen olgulardan biridir. Tekstil mamullerinin renklendirilme işlemlerinde günümüzde genellikle sentetik boyarmaddeler kullanılmaktadır. Ancak insanların kimyasal kökenli maddelere karşı olan önyargıları nedeniyle son zamanlarda doğal boyarmaddelerin kullanımı tekrardan gündeme gelmiştir. Bu kapsamda yapılan bu çalışmada ısırgan otunun keten kumaşların renklendirilmesinde kullanılabilirliği araştırılmıştır. Özellikle mordan maddesi kullanımı olmadan keten kumaşların ısırgan otuyla renklendirilebileceği ve gerekli haslık özelliklerini de gösterebileceği tespit edilmiştir. Bu da özellikle istenilen bir durumdur. Çünkü genellikle mordan maddesi boyarmaddeyi liflere iyi bağlayarak haslık özelliklerini geliştirmektedir. Ancak burada mordan maddesi kullanımı olmadan da gerekli ve yeterli haslık özellikleri sağlanmıştır. Renk verimliliği (K/S) boyama denemelerinde önemli bir faktördür. Isırgan otu kullanılarak yapılan boyama denemelerinde en düşük K/S değerine 1:0,5 boyama konsantrasyonunda şap mordan maddesi kullanılarak yapılan boyama denemesinde ulaşılmıştır ve bu değer 0,38. En yüksek değer ise yine şap mordan maddesi kullanılarak 1:2 boyama konsantrasyonunda yapılan boyama denemesinde elde edilmiştir. Bu değer ise 0,79 olarak karşımıza çıkmaktadır. Çalışma kapsamında kullanılan 6 farklı mordan maddesi yardımıyla da farklı renk tonlarının açığa çıkacağı bulunmuştur. Çalışma genelinde de yapılan ışık ve yıkama haslığı test sonuçları da göstermiştir ki kullanım açısından bu bitkisel boyarmadde kaynağı yeterli derecede haslık değerlerine sahiptir. Sonuç olarak, ısırgan otunun bilindiği gibi farklı alanlarda da kullanım imkanı bulabilirken, ayrıca tekstil boyamacılığında da (keten kumaş) kullanılabileceği tespit edilmiştir.

\section{KAYNAKLAR}

[1] Şanlı, H.S. Kabalcı, O. (2019). Gaziantep yöresinde yetişen sumak (rhus coriaria 1.) bitkisinden elde edilen renklerle yün halı ipliklerinin boyanması. ARIŞ Halı, Dokuma ve Işsletme Sanatları Dergisi, 15, 62-77. 
[2] Şanlı, H.S. (2011). Halı ve kilim ipliklerinin boyanmasında kullanılan renkler ve bu renkleri veren bitkiler. e-Journal of New World Sciences Academy, 6(4), 464-470.

[3] Doğan, Y. Başlar, S. Mert, H.H. Ay, G. (2003). Plants used as natural dye sources in Turkey. Economic Botany, 57(4), 442-453.

[4] Aras Elibüyük, S. Yıldırım, F.F. Koptur Tasan, P. Yumru, Ş. Çörekcioğlu, M. Oktav Bulut, M. (2019). Bir tekstil işletmesinde, doğal ve sentetik boyarmaddelerle boyanmış \%100 pamuklu kumaşların karşılaştırılması. YEKARUM e-Dergi, 4(2), 28-39.

[5] Özdemir, H. (2018). Bodur mürver (sambucus ebulus 1.) ile yün ipliklerin boyanmas1. Çukurova Üniversitesi Mühendislik Mimarlık Fakültesi Dergisi, 33(1), 219-228.

[6] Silva, P.M.S. Fiaschitello, T.R. Queiroz, R.S. Freeman, H.S. Costa, S.A. Leo, P. Montemor, A.F. Costa, S.M. (2020). Natural dye from croton urucurana baill. Bark: extraction, physicochemical characterization, textile dyeing and color fastness properties. Dyes and Pigments, 173, 1-14.

[7] Önem, E. Mutlu, M.M. Günay, S. Azeri, H. (2012). Soğan (allium cepa) yumru dış kabuğundan doğal boyarmadde ekstraksiyonu ve deri boyamada kullanımı. Tekstil ve Mühendis, 19(88), 1-8.

[8] Amutha, K. Grace Annapoorani, S. Sudhapriya, N. (2020). Dyeing of textiles with natural dyes extracted from terminalia arjuna and thespesia populnea fruits. Industrial Crops \& Products, 148, 1-8.

[9] Teker, M.S. (2019). Güneş 1şınları ile doğal boyama (solar dyeing) yöntemi. Uluslararası Bilim, Teknoloji ve Sosyal Bilimlerde Güncel Gelişmeler Seтроzуити, 20-22 Aralık, Ankara, 54-62.

[10] Gokhale, S.B. Tatiya, A.U. Bakliwal, S.R. Fursule, R.A. (2004). Natural dye yielding plants in İndia. Natural Product Radiance, 3(4), 228-234.

[11] Karpuz, E., Karadeniz Danahaliloğlu, H., Erişen Mısırlığlu, S., \& Tekeli, Y., (2012). Isırgan otu (urtica dioica 1.) bitkisinin antioksidan özellikleri ve fenolik içeriği ile yağ asidi kompozisyonunun belirlenmesi. 37 Eylül, Hatay, 121.

[12] Ayan, A.K. Çalışkan, Ö. Çırak, C., (2006). Isırganotu (Urtica spp.)'nun ekonomik önemi ve tarımı. OMÜ. Zir. Fak. Dergisi, 21(3), 357-363.

[13] Yılmaz Aykul, S. Yıldırım, A. Tokgöz Gün, F. Hamamcı, A. (2018). Isırgan otunun tekstildeki yansımaları. Göller Bölgesi Aylık Hakemli Ekonomi ve Kültür Dergisi, 6(69), 5-9.

[14] Kurban, M. (2012). Isırgan otu lifinden üretilen kumaşların ön terbiye işlemlerinin araştırılması. Yüksek Lisans Tezi, Pamukkale Üniversitesi, Fen Bilimleri Enstitüsü, Denizli.

[15] Karabulut, K. (2015). Pamuklu Örme Kumaşlara Doğal Boyalarla Boyama Yoluyla Tek Adımda Renk, UV Koruyuculuk ve Anrtibakteriyellik Kazandırılması. Yüksek Lisans Tezi, Namık Kemal Üniversitesi, Fen Bilimleri Enstitüsü/Tekstil Mühendisliği Anabilim Dalı, Tekirdağ.

[16] Yaver, Ş. (2015). Tekstil Üretiminde Temiz Teknolojilerin Kullanılması Çerçevesinde Kimyasal Modifikasyon Yoluyla Akrilik Liflerinin Doğal Boyalarla Boyanabilirliğinin Geliştirilmesi. Yüksek Lisans Tezi, Namık Kemal Üniversitesi, Fen Bilimleri Enstitüsü/Tekstil Mühendisliği Anabilim Dalı, Tekirdağ.

[17] ISO 105-B02: (1994), Textiles-tests for color fastness - Part B02: Color fastness to artifical light, International Organization for Standardization, Brussels, Belgium.

[18] ISO 105-C10: (2006), Textiles-tests for color fastness - Part C10: Color fastness to washing with soap or soap and soda, Test Condition: Test A (1), International Organization for Standardization, Geneva, Switzerland. 
[19] Duran, K. (2008). Tekstilde Renk Ölçümü ve Reçete Çıkarma. Ege Üniversitesi Tekstil ve Konfeksiyon Araştırma-Uygulama Merkezi Yayını, İzmir, 308. 